\title{
Recovery characteristics following induction of anaesthesia with a combination of thio- pentone and propofol
}

Saifudin Rashiq BM BS, Blair Gallant RRT, Michael Grace PhD, Donald T. Jolly MD FRCPC
The purpose of this study was to determine the rate and quality of recovery when general anaesthesia was induced with a mixture of thiopentone and propofol, compared with thiopentone or propofol alone. Sixty ASA class I and II women scheduled for out-patient laparoscopic surgery underwent induction of anaesthesia with either (i) thiopentone, (ii) propofol, or (iii) a mixture of the two, in a randomized, double-blind fashion. Anaesthesia was then maintained using nitrous oxide, isoflurane and fentanyl. A psychometric test was administered before and after surgery, and the time taken to reach a series of recovery milestones was noted. Patients were discharged as soon as they were ambulant and had satisfactory control of pain and nausea with oral agents. They were telephoned at 24-48 hr later, and asked to rate their experience of a list of side effects on an ordinal scale. Patient groups were demographically comparable and underwent surgery of the same duration. Those receiving thiopentone were discharged after a mean time of $3 \mathrm{hr} 25 \pm$ $58 \mathrm{~min}(S D)$. The corresponding figures for propofol and the thiopentone/propofol mixture were $2 \mathrm{hr} 40 \mathrm{~min}( \pm 49)$ and 2 $\mathrm{hr} 48 \mathrm{~min}( \pm 68)$ respectively. The recovery time between thiopentone and the other two regimes was different $(P<0.05)$. All three groups experienced equally frequent and severe nausea, headache, tiredness and other side effects during the next $24 \mathrm{hr} . \mathrm{It}$ is concluded that induction with a mixture of thiopentone and propofol leads to a similar rate and quality of recovery to that of propofol above. The use of thiopentone alone leads to a slower discharge from hospital when strict discharge criteria are applied. No other differences were apparent during the following $24 \mathrm{hr}$.

\section{Key words}

ANAESTHESIA: outpatient; ANAESTHETICS, INTRAVENOUS: thiopentone/propofol; RECOVERY.

From the Department of Anaesthesia, University of Alberta, 3B2.32 Walter Mackenzie Centre, Edmonton, AB T6G 2C7.

Address correspondence to: Dr. D.T. Jolly.

Accepted for publication 28th July, 1994.
Cette étude vise à déterminer la rapidité et la qualité du réveil après une anesthésie induite avec un mélange de thiopentone et de propofol comparativement au thiopentone et au propofol seuls. Soixante patientes ASA I et II programmées pour une chirurgie laparoscopique ambulatoire sont soumises de façon aléatoire et à double insu à une induction avec (i) thiopentone ou (ii) propofol ou (iii) un mélange des deux. L'anesthésie est ensuite maintenue avec du protoxyde d'azote, de l'soflurane et du fentanyl. Un test psychométrique est adminitré avant et après la chirurgie et les incidents du réveil sont notés. Les patientes sont libérées aussitôt qu'elles peuvent déambuler et qu'une médication orale contrôle la douleur et les nausées. Elles sont rejointes par téléphone 24-48 h plus tard et on leur demande d'évaluer leur expérience sur une échelle ordinale par rapport à une liste d'effets secondaires. Les groupes de patientes sont comparables tant sous l'aspect démographique que celui de la durée de lintervention. Les patientes qui ont reçu du thiopentone sont libérées après (temps $\pm S D) 3 h 25 \pm 58$ min. Les chiffres correspondants pour le propofol et le mélange thiopentone/propofol sont de $2 \mathrm{~h} 40 \mathrm{~min}$ ( \pm 49 ) et $2 \mathrm{~h} 48 \mathrm{~min}$ ( \pm 68$)$. La durée du réveil entre le thiopentone et les deux autres formules est différente $(P<0,05)$. Les trois groupes ont souffert de nausées graves, de céphalée, de fatigue et autres effets secondaires à la même fréquence dans les 24 h suivantes. En conclusion, linduction avec un mélange de propofol et de thiopentone produit un réveil aussi rapide et de même qualité que celui du propofol. Le thiopentone seul prolonge le séjour hospitalier lorsque des critères de congé stricts sont appliqués. On ne note pas d'autres différences pendant les 24 h suivantes.

Propofol and thiopentone are extensively used for the induction of general anaesthesia for ambulatory surgery. ${ }^{1}$ The rapid, clear-headed recovery and the low incidence of nausea and vomiting associated with propofol for short- and medium-duration day surgery procedures are generally held to be advantageous. ${ }^{2}$

Several studies have assessed recovery following propofol or thiopentone anaesthesia for short operative procedures. ${ }^{3,4}$ Few studies have assessed recovery following in- 
duction with either propofol or thiopentone during nitrous oxide and isoflurane anaesthesia for operations of short to medium duration. ${ }^{3}$

Naguib and Sari-Kouzel's finding of a synergistic interaction between propofol and thiopentone ${ }^{5}$ raised the question or whether or not a combination of these two agents would constitute a clinically useful induction regimen. Any clinical benefit obtainable from using such a combination might be expected to be seen in the form of shortened recovery times, improved quality of emergence and improved patient perception of well-being during the postoperative period. No studies have assessed the recovery characteristics of anaesthesia induced with a combination of thiopentone and propofol and maintained with fentanyl, nitrous oxide and isoflurane.

In this study, the primary null hypothesis was that induction of anaesthesia for day-surgery using either propofol, thiopentone or a mixture of the two would lead to no difference in the time needed for patients to become ready for discharge. Secondary hypotheses stated that these groups would show no differences in performance on perioperative psychometric testing or in the incidence and severity of side effects.

\section{Methods}

Hospital Ethics Committee approval and written informed consent were obtained from each participant.

\section{Inclusion and exclusion criteria}

Patients aged 18-65 yr scheduled for gynaecological laparoscopy in the day-surgery unit of the University of Alberta Hospitals during the study period were considered eligible for recruitment. From this group were excluded those of ASA Class III or greater, and anyone taking benzodiazepeines, opioids, antihistamines, barbiturates or other psychotropic agents. Persons not fluent in English or who had known or suspected allergies to egg, soyabean oil or any of the drugs in the study protocol were also excluded.

Sixty-two patients were recruited. Two patients required additional sedation in the recovery room because of a delay in extubation. In both cases, this was due to the administration of a relative overdose of muscle relaxant. These patients were therefore excluded from the study and their randomisation codes were re-used. Thus, 60 patients completed the study.

\section{Randomisation and blinding}

The hospital pharmacy allocated each patient to one of three equal groups by closed-envelope restricted randomisation. Each group was treated identically except for the substance(s) used for induction of anaesthesia. These were thiopentone $25 \mathrm{mg} \cdot \mathrm{ml}^{-1}$ (Group T), propofol 10 $\mathrm{mg} \cdot \mathrm{ml}^{-1}$ (Group P), or a mixture of propofol 5 $\mathrm{mg} \cdot \mathrm{ml}^{-1}$ and thiopentone $12.5 \mathrm{mg} \cdot \mathrm{ml}^{-1}$ (Group TP).

Double blinding was accomplished by preparing a pair of $20 \mathrm{ml}$ syringes for each patient. The syringes contained a clear yellow liquid in one and an opaque white liquid in the other according to the following scheme.

\begin{tabular}{lll}
\hline Group & White liquid & Yellow liquid \\
\hline $\mathrm{T}$ & $\begin{array}{l}\text { Placebo (intralipid 10\% } \\
\text { (Clintec)) }\end{array}$ & $\begin{array}{l}\text { Thiopentone } 25 \mathrm{mg} \cdot \mathrm{ml}^{-1} \\
\text { (Pentothal (Abbott)) }\end{array}$ \\
$\mathrm{P}$ & $\begin{array}{l}\text { Propofol } 10 \mathrm{mg} \cdot \mathrm{ml}^{-1} \\
\text { (Diprivan, (ICI Pharma)) }\end{array}$ & $\begin{array}{l}\text { Placebo (Berocca-C vitamin } \\
\text { concentrate (Roche) in DSW) }\end{array}$ \\
$\mathrm{TP}$ & $\begin{array}{l}\text { Propofol } 5 \mathrm{mg} \cdot \mathrm{ml}^{-1} \\
\text { (Diprivan in DSW) }\end{array}$ & $\begin{array}{l}\text { Thiopentone } 12.5 \\
\mathrm{mg} \cdot \mathrm{ml}^{-1}(\text { Pentothal in water) }\end{array}$ \\
\hline
\end{tabular}

Careful colour-matching between the syringe pairs was undertaken. The syringes were taped together and their plungers depressed as one. The contents of both syringes were injected simultaneously via a Y-piece during induction of anaesthesia. Provision was made for the contents of any syringe pair to be made known to the investigator in the case of an emergency.

\section{Procedure}

All patients were unpremedicated. A test of hand-eye coordination, the Aiming Total Test, was administered three times $>20 \mathrm{~min}$ before surgery. This test requires the subject to place a pencil dot in the centre of as many $2 \mathrm{~mm}$ circles on a test sheet as possible during $90 \mathrm{sec}$. Its use in such circumstances is described. 6,7 The score is the number of dots correctly placed. This test was repeated at one and two hours after surgery.

On arrival in the operating room, an infusion of Ringer's lactate was allowed to run freely via a 20 gauge cannula in a hand vein. A continuous ECG, automated BP cuff, pulse oximeter, oxygen analyser, capnometer and nerve stimulator were used in all cases. Three milligrams d-tubocurarine were administered $i v$. Anaesthesia was induced three minutes later by one of two investigators according to the following protocol: a stopwatch was started, and a bolus of $0.1 \mathrm{ml} \cdot \mathrm{kg}^{-1}$ from each syringe was injected over four seconds into the port of the $i v$ line closest to the patient. Another anaesthetist maintained verbal contact with the patient and checked continuously for loss of the eyelash reflex, this having been defined as the end-point of induction. If this had not occurred $30 \mathrm{sec}$ after the beginning of the bolus injection, a further drug was given at $0.25 \mathrm{ml} \cdot \mathrm{sec}^{-1}$ until either the induction was complete or the entire contents of the syringe pair had been given. The time and volume of injectate needed to achieve this were noted. Fentanyl 2 $\mu \mathrm{g} \cdot \mathrm{kg}^{-1}$ and succinylcholine $100 \mathrm{mg}$ were administered, a cuffed endotracheal tube was passed, and the patient's 
TABLE I Demographic data and operative procedure performed by group (SD)

\begin{tabular}{lcll}
\hline Group $(n=20)$ & $T$ & $P$ & $T P$ \\
\hline Age: $y r$ & $31.0(5.2)^{*}$ & $35.1(4.7)^{*}$ & $33.1(6.4)$ \\
Surgery time: min & $1.8(5.25)$ & $22.5(7.6)$ & $18.8(6.7)$ \\
Weight: kg & $68.8(11.7)$ & $71.0(16.6)$ & $67.6(15.6)$ \\
& & & \\
Laparoscopic procedure & 5 & 6 & 3 \\
Diagnostic & 6 & 3 & 5 \\
Hydrotubation & 9 & 7 & 10 \\
Tubal ligation & 0 & 4 & 2 \\
Other & 0 & & \\
\hline
\end{tabular}

$* P<0.05$ Group T vs Group $P$.

lungs were ventilated to normocapnia with $70 \%$ nitrous oxide in oxygen, delivered by a semiclosed circle breathing system using a total fresh gas flow of $6 \mathrm{~L} \cdot \mathrm{min}^{-1}$. Isoflurane $0-3 \%$ inspired was added to maintain adequate anaesthesia. Muscle relaxation was supplemented when necessary with further succinylcholine, atracurium or vecuronium at the discretion of the attending anaesthetist. Carbon dioxide was used for creating the pneumoperitoneum.

The end of surgery was defined as the time of completion of the final skin suture. At this point, the residual effect of any non-depolarising relaxant was reversed with neostigmine $3 \mathrm{mg}$ and glycopyrrolate $0.4 \mathrm{mg}$ and the patient's lungs ventilated with $100 \%$ oxygen until the return of spontaneous respirations. After transfer to the adjacent recovery room, the time taken to achieve each of a number of milestones in the recovery process was noted. The endotracheal tube was removed when airway protective reflexes had fully returned. Morphine $3 \mathrm{mg}$ $i v$ and prochlorperazine $5 \mathrm{mg} i v$ were provided for pain and nausea as needed.

Subjects were transferred to the day ward at the discretion of the attending anaesthetist. The Aiming Total Test was administered at one and two hours postoperatively. Patients were encouraged to sit, stand, drink and walk as soon as they felt able. Meperidine $50-100 \mathrm{mg}$ im and dimenhydrinate $25-50 \mathrm{mg}$ im were given for pain and nausea at patients' request. Immediately after successfully taking oral fluids without nausea and walking to the bathroom without assistance, subjects were deemed fit for discharge. An investigator remained in continuous attendance from induction of anaesthesia until this time in order to ensure that these criteria were uniformly applied.

Follow up took place by telephone at $24-48 \mathrm{hr}$ after surgery. All subjects were asked to quantify the extent of any nausea, sore throat, muscle pains, headache, backache, tiredness, hangover or dizziness experienced during the first $24 \mathrm{hr}$ as "none," "mild," "moderate" or "severe."
TABLE II Induction time, volume of induction agent required and dose by group (SD)

\begin{tabular}{llll}
\hline & $T$ & $P$ & $T P$ \\
\hline Time, sec & $63(24)$ & $76(22)$ & $73(21)$ \\
Volume, ml & $14(4)^{*}$ & $17(3)^{*}$ & $15(3)$ \\
Thiopentone, & & & \\
$\quad \mathrm{mg} \cdot \mathrm{kg}^{-1}$ & $5.2(1.5)$ & 0 & $3.0(0.7)$ \\
Propofol, $\mathrm{mg} \cdot \mathrm{kg}^{-1}$ & 0 & $2.3(0.6)$ & $1.2(0.3)$ \\
\hline
\end{tabular}

${ }^{*} P<0.05$ Group T vs Group $P$

TABLE III Time taken after completion of surgery to achieve recovery milestones, by group (SD)

\begin{tabular}{|c|c|c|c|}
\hline & $T$ & $P$ & $T P$ \\
\hline $\begin{array}{l}\text { Opens eyes to } \\
\text { command, min }\end{array}$ & $8.1(5.00)$ & $6.75(5.45)$ & $8.22(7.56)$ \\
\hline Extubation, min & $6.68(3.65)$ & $7.42(5.87)$ & $7.78(6.55)$ \\
\hline $\begin{array}{l}\text { States correct date of } \\
\text { birth, } \min \end{array}$ & $10.97(5.77)$ & $8.80(5.67)^{*}$ & $10.12(7.70)$ \\
\hline Sits up unaided, $\min$ & $55(49)$ & $30(15)$ & $53(47)$ \\
\hline Takes oral fluids, hr & $1.85(0.73)$ & $1.35(0.63)$ & $1.42(0.62)$ \\
\hline Stands unaided, $\mathrm{hr}$ & $2.72(1.00) \dagger$ & $1.96(0.70)$ & $2.00(0.80)$ \\
\hline Discharged, $\mathrm{hr}$ & $3.42(0.96) \dagger$ & $2.67(0.82)$ & $2.80(1.13)$ \\
\hline
\end{tabular}

$* P<0.05$ Group $P$ vs Groups T and TP.

$\dagger P<0.05$ Group $\mathrm{T}$ vs Groups $\mathrm{P}$ and $\mathrm{TP}$.

\section{Statistical methods}

All data were coded and entered into a computing system. Coded data were spot-checked for accuracy, and a random sample extracted and compared with raw data. Groups were compared at baseline and at outcome for differences using analysis of variance and chi-squared tests. All analyses were done before the randomisation code was broken. The significance level for the primary hypothesis was 0.05 and Bonferroni's corrections were applied where appropriate.

\section{Results}

Table I contains demographic and operative characteristics of each group. There was a difference between the mean ages of groups $P$ and $\mathrm{T}(P<0.05)$ but the absolute difference was small. The groups were of comparable weight and underwent operations of similar duration. The most frequently performed procedure was laparoscopic tubal ligation, accounting for $35-50 \%$ of the cases in each group.

Table II gives the amounts of each agent needed to induce anaesthesia, and the time taken. The times show no differences among groups. Two patients each in Groups T and TP and five in Group P required the entire contents of their syringes.

Table III gives the speed with which each group 
TABLE IV Aiming total test scores, by group (SD)

\begin{tabular}{|c|c|c|c|c|c|c|c|}
\hline \multirow[b]{2}{*}{ Group } & & \multicolumn{2}{|l|}{$T$} & \multicolumn{2}{|l|}{$P$} & \multicolumn{2}{|l|}{$T P$} \\
\hline & & Score & $\begin{array}{l}\text { \% of } \\
\text { best } \\
\text { score }\end{array}$ & Score & $\begin{array}{l}\% \text { of } \\
\text { best } \\
\text { score }\end{array}$ & Score & $\begin{array}{l}\% \text { of } \\
\text { best } \\
\text { score }\end{array}$ \\
\hline \multirow[t]{3}{*}{ Preoperative tests: } & $1^{*}$ & $171(39)$ & 88 & $181(32)$ & 86 & $161(32)$ & 85 \\
\hline & $2^{*}$ & $186(43)$ & 96 & $196(29)$ & 94 & $175(35)$ & 92 \\
\hline & $3^{*}$ & $194(43)$ & 100 & $209(28)$ & 100 & $191(34)$ & 100 \\
\hline \multirow[t]{2}{*}{ Postoperative tests: } & $1 \dagger$ & $121(71)$ & 62 & $163(54)$ & 78 & $119(63)$ & 62 \\
\hline & $2 \ddagger$ & $161(55)$ & 83 & $180(54)$ & 86 & $146(51)$ & 76 \\
\hline
\end{tabular}

*All three tests performed over a $20 \mathrm{~min}$ period.

†At one hour postoperatively.

$\ddagger$ At two hours postoperatively.

TABLE $Y$ Side effects in hospital by group $(n)$

\begin{tabular}{lcrr}
\hline & $T$ & $P$ & $T P$ \\
\hline Recalled pain or burning on injection & $2^{*}$ & 10 & 10 \\
Vomited & 6 & 3 & 3 \\
Received parenteral analgesia & 16 & 13 & 12 \\
Received parenteral antiemetic & $15 \dagger$ & 6 & 9 \\
\hline
\end{tabular}

$* P<0.05$ Group T vs Group P and Group T vs Group TP.

$\dagger P<0.05$ Group T vs Group P and Group T vs Group TP.

achieved their recovery milestones. There was no difference among the groups in the time taken to open eyes to command, to extubation, to earliest unassisted sitting or the taking of oral fluids. Group P were able to state their dates of birth correctly more rapidly than the other two groups $(P<0.05)$, but the maximum mean difference between groups for this milestone was only $2 \mathrm{~min}$ $10 \mathrm{sec}$. Group $\mathrm{T}$ were slower to achieve unassisted standing and discharge ( $P<0.05$ vs Groups $P$ and TP). The shortening in discharge time compared to that of Group $\mathrm{T}$ was 37 minutes (18\% of total postoperative stay) for Group TP and 45 min (22\%) for Group P. No patient required admission to hospital.

There was no difference between groups in preoperative performance and all showed improved scores with the three practice attempts (Table IV). A decrease in score was seen at one hour postoperatively, but some recovery took place during the second hour in all groups. No group was able to equal its peak performance after surgery.

Data concerning patient wellbeing in hospital are given in Table V. Burning or pain on injection were recalled by half of Groups $\mathbf{P}$ and TP, but only two patients in Group T $(P<0.05)$. The number of patients from each group who vomited in hospital was not significantly different. Parenteral analgesia was required by more than half of each group at some point postoperatively. Sig-
TABLE VI Side effects during next $24 \mathrm{hr}$ by group (n)

\begin{tabular}{llrrr}
\hline & & $T$ & $P$ & $T P$ \\
\hline Nausea & None/mild & 14 & 15 & 15 \\
& Moderate/severe & 6 & 5 & 5 \\
Headache & None/mild & 17 & 17 & 19 \\
& Moderate/severe & 3 & 3 & 1 \\
Tiredness & None/mild & 7 & 11 & 6 \\
& Moderate/severe & 13 & 9 & 14 \\
Hangover & None/mild & 15 & 19 & 17 \\
& Moderate/severe & 5 & 1 & 3 \\
Dizziness & None/mild & 15 & 17 & 15 \\
& Moderate/severe & 5 & 3 & 5 \\
Sore throat & None/mild & 12 & 10 & 9 \\
& Moderate/severe & 8 & 10 & 11 \\
Backache & None/mild & 17 & 19 & 16 \\
& Moderate/severe & 3 & 1 & 4 \\
Myalgia & None/mild & 9 & 13 & 10 \\
& Moderate/severe & 11 & 7 & 10 \\
\hline
\end{tabular}

$P=$ NS across all groups.

nificantly fewer patients in Groups $\mathrm{P}$ and $\mathrm{TP}$ required parenteral antiemetics than in Group $\mathrm{T}(P<0.05)$

In Table VI, patients' subjective assessment of eight side effects experienced during the first $24 \mathrm{~h}$ after surgery are given. There were no differences between the groups.

\section{Discussion}

The major finding of this study was that the induction of general anaesthesia with propofol leads to recovery that is faster than that seen after induction with thiopentone, but no faster than that seen after the use of a mixture of the two agents. The primary null hypothesis is therefore rejected. There was no difference between the groups in performance on a test of psychomotor functioning administered during recovery. Those receiving thiopentone reported less pain on injection, but required parenteral antiemetics more frequently. The number and 
severity of side effects experienced during the day after operation was the same in each group.

The primary impetus for this work was the study of Naguib and Sari-Kozuel. ${ }^{5}$ Using isobolographic analysis, they demonstrated that the combination of propofol and thiopentone showed synergistic properties for the induction of anaesthesia. Their selected end-point was the inability of the subject to open his eyes to command 60 sec after the end of the injection and the $\mathrm{ED}_{50}$ potency ratio of propofol to thiopentone was shown to be 1:1.604.

The $\mathrm{ED}_{50}$ value is useful for comparing the potency of anaesthetic induction agents. However, in clinical practice, it is necessary to provide the dose of induction agent that achieves the desired end-point in all patients. Isobolographic analysis is an excellent technique for determining whether or not combinations of drugs are synergistic. ${ }^{8.9}$ However, the relevance of the isobolographic definition is questionable when the clinical response of each drug is related to the logarithm of the dose. ${ }^{15}$ This is true for the probability of successful induction of anaesthesia with both induction agents in the current study. ${ }^{11}$ In addition, Naguib and Sari-Kozuel held the thiopentone dose constant while varying the dose of propofol. Since synergistic interaction may only be apparent within specific dose ranges of two drugs, it is important to vary the doses of both drugs and study a range of combinations. ${ }^{10}$ Furthermore, isobolographic analysis does not predict the dose combination that has maximal synergistic effect. ${ }^{10}$

Edelist observed that propofol was 2.2 times as potent as thiopentone, assuming that clinical judgement was an accurate assessment of induction. ${ }^{12} \mathrm{He}$ defined the endpoint of induction of anaesthesia as the cessation of counting by the subject and their failure to respond to command. This can be achieved with a smaller dose of either propofol or thiopentone than can the loss of the eyelash reflex. Given, therefore, that the true equipotency ratio of these drugs for achieving the loss of the eyelash reflex is not known, we used the estimations of Edelist and others, ${ }^{13,14,15}$ and selected an arbitrary equipotency ratio of 1:2.5, which facilitated the preparation of the syringes by the pharmacy. Since the dose was titrated to effect in our study, it was impossible for any patient to have a failed induction.

That faster recovery is seen after propofol than thiopentone is well recognised: Edelist ${ }^{12}$ reported awakening times of $4.6 \mathrm{~min}$ after propofol and $6.6 \mathrm{~min}$ after thiopentone in his study of unpremedicated outpatients undergoing abortions under intravenous anaesthesia with nitrous oxide supplementation. The definition of wakefulness used in the study may have differed from those used here but the results are similar to the times taken for Groups $P$ and $T$ in the present study to open their eyes to command. Edelist's patients recovered between $18 \%$ and $30 \%$ faster after propofol than thiopentone, depending on the recovery end-point chosen. In this study, the decrease in time to discharge was $22 \%$ with propofol. Other workers have reached similar conclusions after studying subjects under total intravenous anaesthesia, intravenous anaesthesia supplemented with nitrous oxide, and balanced techniques incorporating volatile agents and opioids. ${ }^{3,16-21}$

The mean doses of thiopentone and propofol given to Groups $\mathrm{T}$ and $\mathrm{P}\left(5.2 \mathrm{mg} \cdot \mathrm{kg}^{-1}\right.$ and $2.3 \mathrm{mg} \cdot \mathrm{kg}^{-1}$ respectively), are in accord with ranges described by others. ${ }^{12,19}$ The similarity of the side-effect profiles observed in all three groups at $24 \mathrm{hr}$ after surgery is consistent with the results of other work. In comparing thiopentone and propofol as sole anaesthetic agents Kashtan $e t$ al. ${ }^{19}$ administered a seventeen-point visual analogue scale questionnaire 24 and $48 \mathrm{hr}$ after surgical procedures of intermediate duration, while Sanders et al. elicited the presence or absence of thirteen different symptoms at either 24 or $48 \mathrm{hr}$ after short outpatient gynaecological procedures. ${ }^{21}$ No differences were found.

The side-effect profiles of thiopentone and propofol have been compared in a number of studies. Killian $e t$ al. described vomiting in hospital after one of a range of minor surgical procedures in 5 of $33(15 \%)$ of patients receiving propofol and 10 of $29(34 \%)$ of those receiving thiopentone/ isoflurane. ${ }^{16}$ The corresponding figures from this study are $15 \%$ and $30 \%$ respectively. Pain or burning on injection were experienced by $50 \%$ of patients receiving propofol in this study, which compares with other work. ${ }^{19}$

Recovery from anaesthesia can be measured in many different ways. We elected to use measurements of time to return of function and self-reported symptom profiles as our primary measures of outcome since, feeling these to be the most relevant to clinical practice. The wide variety of side effects experienced after anaesthesia necessitates the posing of a large number of questions if a systematic search for them is to be adequate. It is recognized that this increases the risk of a spurious difference being recorded. We used fewer symptom categories than either of the other two most comparable studies in this respect, ${ }^{19,21}$ and are reassured by the absence of differences between the groups. Three of the side-effect categories (sore throat, myalgia and backache) were included precisely because their prevalence was not felt likely to be affected by the type of induction agent used. The absence of differences in these categories is also reassuring.

The Aiming Total Test confirmed that eye-hand coordination was adversely affected following anaesthesia. Its failure to detect differences even between the thiopentone and propofol groups reflects the difficulty ex- 
perienced by other workers in correlating psychometric test data with clinical recovery profiles. ${ }^{22}$

The preparation of the mixture of propofol and thiopentone in the same vessel was avoided because of the absence of published stability data for this combination. The drugs coursed together in the same $i v$ tubing for a small but finite distance. Theoretical considerations indicate that neither active drug would precipitate under these conditions, and no unexpected adverse local or systemic effects were seen in any patient.

\section{Conclusion}

Induction of anaesthesia with a mixture of propofol and thiopentone provides equally rapid and qualitatively similar recovery to that afforded by propofol alone, in healthy women undergoing outpatient laparoscopy. Both regimes are superior to thiopentone alone in this respect. The difference is no longer apparent on the day after surgery.

\section{Acknowledgements}

We are grateful for the cooperation of the gynaecologists, anaesthetists, Day Surgery Recovery nurses and Day Ward nurses of the University of Alberta Hospitals, and for the invaluable assistance of Vera Jordan, Jill Moore, and Darcia Wassarab-Rowland of the Department of Pharmacy.

\section{References}

1 White PF. General anesthetic techniques for ambulatory surgery. American Society of Anesthesiologists' Annual Refresher Course Lectures 1993; 121: 1-7.

2 Twersky RS. The pharmacology of anesthetics used for ambulatory surgery. American Society of Anesthesiologists' Annual Refresher Course Lectures 1993; 255: 1-7.

3 Gupta A, Larsen LE, Sjöberg F, Lindh ML, Lennmarken $C$. Thiopentone or propofol for induction of isofluranebased anaesthesia for ambulatory surgery? Acta Anaesthesiol Scand 1992; 36: 670-4.

4 Henriksson B-A, Carlsson P, Hallén B, Hägerdal M, Lundberg $D$, Pontén $J$. Propofol vs thiopentone as anaesthetic agents for short operative procedures. Acta Anaesthesiol Scand 1987; 31: 63-6.

5 Naguib M, Sari-Kouzel $A$. Thiopentone-propofol hypnotic synergism in patients. Br J Anaesth 1991; 67: 4-6.

6 James FM III. The effects of cyclopropane anesthesia without surgical operation on mental function of normal man. Anesthesiology 1969; 30: 264-72.

7 Sanders LD, Isaac PA, Yeomans WA, Clyburn PA, Rosen $M$, Robinson JO. Propofol-induced anaesthesia. Anaesthesia 1989 ; 44: $200-4$.

8 Berenbaum $M C$. Synergy, additivism and antagonism in immunosuppression. A critical review. Clin Exp Immunol 1977; 28: 1-18.
9 Halsey MJ, Wardley-Smith B, Green CJ. Pressure reversal of anaesthesia - a multi-side expansion hypothesis. $\mathrm{Br} \mathrm{J}$ Anaesth 1978; 58: 1091-7.

10 McClune S, McKay AC, Wright PMC, Patterson CC, Clarke RSJ. Synergistic interaction between midazolam and propofol. Br J Anaesth 1992; 69: 240-5.

11 Van Hemelrijck J, Muller P, Van Aken H, White PF. Relative potency of eltanolone, propofol, and thiopental for induction of anesthesia. Anesthesiology 1994; 80: 36-4l.

12 Edelist $G$. A comparison of propofol and thiopentone as induction agents in outpatient surgery. Can $J$ Anaesth 1987; 34: 2; 110-6.

13 Grant IS, Mackenzie $N$. Recovery following propofol ("Diprivan") anaesthesia - a review of three different anaesthetic techniques. Postgrad Med J 1985; 61 (Suppl 3): 133-7.

14 Herbert M, Makin SW, Bourke JB, Hart EA. Recovery of mental abilities following general anaesthesia induced by propofol ('Diprivan') or thiopentone. Postgrad Med J 1985; 61 (Suppl 3): 132.

15 Briggs $L P$, White $M$. The effects of premedication on anaesthesia with propofol ('Diprivan). Postgrad Med J 1985; 61 (Suppl 3): 35-7.

16 Killian A, Hamilton P, Tierney M. Propofol versus thiopental-isoflurane in outpatient surgical procedures. Can J Hosp Pharm 1992; 45: 139-44.

17 Chittleborough MC, Osborne GA, Rudkin GE, Vickers $D$, Leppard PI, Barlow J. Double-blind comparison of patient recovery after induction with propofol or thiopentone for day-case relaxant general anaesthesia. Anesth Intensive Care 1992; 20: 169-73.

18 Runcie CJ, Mackenzie SJ, Arthur DS, Morton NS. Comparison of recovery from anaesthesia induced in children with either propofol or thiopentone. $\mathrm{Br} \mathrm{J}$ Anaesth 1993; 70: 192-5.

19 Kashtan H, Edelist G, Mallon J, Kapala D. Comparative evaluation of propofol and thiopentone for total intravenous anaesthesia. Can J Anaesth 1990; 37: 170-6.

20 Boey WK, Kumar A. Comparison of propofol and thiopentone as induction agents for laparoscopy. Singapore Med J 1991; 32: 150-3.

21 Sanders LD, Clyburn PA, Rosen PA, Robinson JO. Propofol in short gynaecological procedures. Comparison of recovery over 2 days after anaesthesia with propofol or thiopentone as sole anaesthetic agent. Anaesthesia 1991; 46: 451-5.

22 Ryom C, Flarup M, Suadicani P, Palm T, Mikkelsen S, Gyntelberg $F$. Recovery following thiopentone or propofol anaesthesia assessed by computerized coordination measurements. Acta Anaesthesiol Scand 1992; 36: 540-5. 